\title{
MODELS OF RESOURCES ALLOCATION WITHIN THE SUSTAINABLE AGRICULTURAL HOLDINGS
}

\author{
Associate Professor PhD Burja Camelia, “1 Decembrie 1918” University of Alba Iulia, \\ cameliaburja@yahoo.com \\ Professor PhD Todea Nicolae, “1 Decembrie 1918” University of Alba Iulia,ntodea@ uab.ro
}

\begin{abstract}
The agricultural holdings generate a very strong impact on the environment and they also have numerous implications for the economic and social life of rural areas. The improvements of the agricultural holdings' economic, ecological and social effects are the main directions which can contribute to initiating or intensifying their sustainability. This paper highlights some possibilities to optimize the use of agricultural resources allocated to a sustainable development, with a special attention for the elements of the natural capital. The presented models can substantiate the agro-technical decisions within the framework of eco-efficiency actions aimed to achieve sustainability at the farming microeconomic level.
\end{abstract}

Keywords: agricultural holdings, natural resources, allocation models, sustainable development

JEL: $Q 16, Q 56$

\section{Introduction}

In the frame of the contemporary economic environment, sustainable development has become a stringent condition on which the general welfare depends, manifested both at the economic level proper, and at the level of the population's life and of the environment quality, for a long period.

The need to adopt the sustainable development perspective has been of world interest for over two decades (the Brudtland Report, 1987) and it has been integrated into all policies adopted by the European Union member states, as a central objective. As a recent integrated state, Romania has adopted the objectives established at the EU level and the methodological prescriptions of the European Commission into the document entitled The National Strategy for the Sustainable development of Romania, time horizons 2013-2020-2030. This document highlights the main action directions for integrating and applying the principles of sustainable development in the next period.

The objectives formulated within the Strategy referring to the agricultural sector of economy, aim at the sustaining of the population food security by the farming activities through valorising the advantages that Romania has, in a comparative way, but only with respects of all limits due to demand of the environment protection and preservation.

According to their activity, the agricultural holdings are economic systems that can generate a high impact on the environment. The sustainability of farming activities can be identified by using the various elements of the natural capital, and namely the following indicators: nutrients balance, soil quality, plant diversity, water pollution, chemical wastes contained by the agricultural products. Also, indicators of the human capital quality (education level, age etc) or of economic aspects (agricultural revenues, the total performance of the production factors, debts level etc) are useful in assessing sustainability.

One can appreciate that at the whole ecological capital of Romania, the productive agricultural systems represent about $45 \%$. Their role is to sustain the population agro food consumption based on the vegetable or animal productions which are obtained [SDDR, 2008]. 
Due to the division of the land as a result of the Land Law, nowadays there is a high number of agricultural holdings (over 4 million) which generally have a subsistence character so that, their economic activities interacting with the environment, are not efficient and cannot ensure the food resources at a satisfactory level,.

There are also, other reasons that can strongly affect the activity and results of the farms. Their poor performance is due to the quality of the natural factors that are important production resources within the agricultural sector. So, only the soil erosion phenomena affect the agricultural activity in a share of $40 \%$ and they lead to a production loss of about 150 million tons yearly. There are 2.5 million ha worn out lands, uncultivated lands (over 17\% in 2006) and a strong influence of the climate factors (high temperatures, few rainfalls) that without an extended irrigation system, have a negative influence on the agricultural capacity - the water demands of the plants are not ensured in the necessary dose [SDDR, 2008].

In order for agricultural systems to obtain the characteristic features of the sustainable growing models, it is necessary to take some important restructuring actions concerning the specific development strategies and policies, the functioning and production structure of the holdings, the improvement of the internal and institutional organizing framework, the introduction of the ecoefficiency criteria for all productive actions, the reduction of the agricultural labour force, the improvement of the sustaining capacity of the farming activities by the natural capital (in the world, the present bio-productive capacity of the natural capital elements is reduced; it is almost half of the entire potential) [Nijkamp, 2008].

Within this context, the implementation of sustainable agricultural systems within the holdings requires a series of actions that ensure the increase of their competitiveness and performance, sure and constant incomes for farmers, agro food safety for population, the protection and improvement of natural resources.

The sustainable development of agricultural holdings, in view of increasing productive efficiency under the eco-efficiency criteria, implies the use of advantageous agricultural techniques, and namely:

- measures of land meliorations: works for drying up, embankments, fight against soil erosion, desalinization, correction of the soil chemical composition, fertilization works;

- optimum allocation of resources depending on the productive potential of the land and applied technologies. Rational utilization of material resources (fertilizers, seeds, biological material), mechanic energy sources (agricultural machines, installations) and labour force, which all contribute to production resources saving through avoiding the wasting phenomenon, consumption diminishing and concerning the sustainable aspects, they are able to ensure the growth of physical production and of its economic effects;

- rational organization of the territory according to purpose of usage in accordance with the soil favourability for various agricultural activities or crops. In a sustainable development system, it is necessary to re-organize the cultivated lands so that they agree with the new management and resource administration practices; [Bijaya, 2008]

- using crops rotation - it produces positive effects on the soil structure, the plants' health and production increase;

- optimum combination of the agricultural branches - it reduces the commercial inputs through complementarities between the agricultural branches, that means using of the vegetal or animal wastes as raw materials for other activities etc.

\section{The optimum use of material resources}

The land melioration measures are diversified and they produce the beneficial effects both at the economic level and concerning the qualitative rehabilitation of the natural factors used within the holdings' activity. 
The agricultural melioration works aim at the correction of the soils' quality and at ensuring the nutrients that plants need in order to grow. Their final effects are found in the better bioproductive capacity of soils and in the better ecological conditions for crops. From the sustainable development perspective, this means a structural transformation of a natural factor according with the principles of this development model, resulting from the interaction of the agricultural economy of holdings with the environment.

The gain in productive capacity of one land registered after melioration works varies depending on the land degradation degree, on the crops and on the sort of the melioration work that was applied.

Besides the application of some land melioration measures, the practical use of the optimum allocation techniques of resources is farming is an important element of strategy to convert the agricultural conventional systems towards the sustainable ones.

The optimum material resources allocation focuses on the sustainable development objective of saving resources, which are generally limited and some of which are not renewable. Another aim is to establish optimum amounts of resources which can meet the plants' needs from a technological point of view and on observing the eco-efficiency conditions.

The sustainable farming systems are characterized by the alternative technologies for crops breeding that refers to reducing the consumption of synthesis chemical substances, by the use of some biological methods to fight pest and diseases, by using organic fertilizers of plant or animal origin (manner, muck, compost, guano, plants residues), by reducing the time of mechanized work and extending the manual works etc.

Even when an agricultural holding has sufficient material resources, the sustainable development requires their optimum allocation, so that the resources can be protected and contribute to enhance the soil efficiency, due to the allocation of the most suitable dose according with the plants' needs.

In the following pages, we study the optimum allocation of the organic resources used for soil fertilization, within a farm which has an arable surface of 800 ha cultivated with maize in a monoculture system. In the analyzed year, a conventional farming system was used and we have studied the effects of passing to a sustainable system using information for 5 experimental hectares. The farm can benefit from cheap resources for fertilizing its land, produced by the animal husbandry farm of the agricultural holding (manure). The necessary data are presented in table 1.

Table no. 1

Indicators for establishing the optimum dose of natural fertilizer for a maize crop

\begin{tabular}{|c|c|c|}
\hline Land & $\begin{array}{c}\text { Organic fertilizer } \\
\text { (to/ha) }\end{array}$ & $\begin{array}{c}\text { Physical production } \\
\text { in sustainable system } \\
\text { (to/ha) }\end{array}$ \\
\hline 1 & 40 & 4.11 \\
\hline 2 & 50 & 4.47 \\
\hline 3 & 60 & 4.52 \\
\hline 4 & 70 & 4.62 \\
\hline 5 & 80 & 4.50 \\
\hline
\end{tabular}

Source: experimental information of the holding

As the information show variations of the production obtained through a sustainable process, depending on the dosage of organic fertilizer, we have used the production functions method, in order to determine that optimum amount of nutrient which can ensure both increasing of the natural fertility of soil and a maximum of economic effects.

In order to identify the type of connection between the organic crop of maize and the quantity of organic fertilizer used, it is necessary to show the graphic representation. 
The inter-dependence of a parabolic type conducts to the use of the corresponding production function, which has the expression:

$$
Q=a+b \cdot I+c \cdot I^{2}
$$

where: $Q$ is production obtained in a sustainable system;

$I$ - the amount of organic fertilizer applied.

In order to find out the unknown coefficients of production function $a, b$ and $c$, we use the method of least squares which supposes to solve an equations system of this form:

$$
\begin{aligned}
& n a+b \sum_{j=1}^{n} I_{j}+c \sum_{j=1}^{n} I_{j}^{2}=\sum_{j=1}^{n} Q_{j} \\
& a \sum_{j=1}^{n} I_{j}+b \sum_{j=1}^{n} I_{j}^{2}+c \sum_{j=1}^{n} I_{j}^{3}=\sum_{j=1}^{n} I_{j} Q_{j} \\
& a \sum I_{j}^{2}+b \sum I_{j}^{3}+c \sum I_{j}^{4}=\sum I_{j}^{2} Q_{j}
\end{aligned}
$$

If we substitute the data in system, it will be:

$$
\begin{aligned}
& 5 a+300 b+19000 c=22,22 \\
& 300 a+19000 b+1260000 c=13425,5 \\
& 19000 a+1260000 b+86740000 c=85461
\end{aligned}
$$

Solving the equations system leads to the following results:

$$
a=1,676 ; \quad b=0,0873 \text { and } c=-0,00065
$$

The determined form of production function using the findings is:

$$
Q=1,676+0,0873 \cdot I-0,00065 \cdot I^{2}
$$

The interpretation from a technical view of obtained function means finding out the optimum amount of natural fertilizer necessary for maize breeding in a sustainable system. This can ensure a maximum of quality according with the specific standards of ecological products, on the same time providing the organic material for soil fertilization. It can be determined based on the first derivate of production function depending on the organic fertilizer:

$$
\begin{aligned}
& \frac{d Q}{d I}=0 \quad b+2 \cdot c \cdot I=0 \\
& I=-\frac{b}{2 \cdot c} ; \quad I=\frac{0,0873}{2 \cdot 0,00065}=67,2 \text { to } / \text { ha }
\end{aligned}
$$

An ecological fertilizing system through the application of a dosage of 67.2 to/ha leads to a better crop than in the case of no administration of the fertilizer. The average production obtained without nutrients of the surface of 5 ha was of 2.89 to and the production increase was of 1.81 to/ha, which was an improvement of the soil productive efficiency by $61.5 \%$. Extending that ecological 
technology element to a bigger area will multiply the economic advantages. For the environment,, this implies less pollution because chemical fertilizers are no longer used.

In 2007, the maize was sold for 10 euro/to, so that the sustainable system practised by the agricultural holdings brought a gain of 188 euro/ha. These results suggest important possibilities to increase economic efficiency, only based on the perfection of the farming technological elements and a rational utilization of the disposal production factors. resources.

The algorithm used is valid also, in the cases of optimum allocation of the other material

\section{Rational use of the land}

Adopting other agro-technical measures for realizing eco-efficiency within the sustainable holdings implies to introduce the rotation system of crops within the arable lands. The growing of different crops, in recurring succession on the same land contrasts with monoculture cropping. It focuses on obtaining many advantages of economic, social, technique and ecological type based on programming of the optimum crops. The crop rotation schema (extent, internal organization, type) depends on the soil conditions, climate, irrigation and fertilization systems and on the economic performance of the land for the previous years [Zahiu, 2003].

Due to the fact that crop rotation is a system which ensures a balance between plants, soil and farming technologies, $\mathrm{i}$ is an essential element of sustainable holdings' organization and functioning. Some of its positive outcomes are [Voicu, 2003]:

- it improves soil fertility (increases the humus amount, lowers the acidity) due to the cultivated crops type;

- amelioration of the lands with low performance in order to increase the potential for high levels of production in future years;

- the crops' health improves in a natural way;

- it prevents weed, pest or disease problems without the use of chemical substances;

- it prevents soil erosion and degradation.

The use of crop rotation in order to achieve the objectives of sustainable development, requires in the first place to establish the crops' structure, that means those crops which are better suited for the type of the agriculture holdings, assessed based on the holdings' data about the material, human and financial resources or technological elements and the natural capital etc.

The crops' structure within the rotation of land can be determined by using the linear programming method. The mathematical model contains location restrictions resulted from the natural and biological conditions, technological restrictions given by the need for crop succession in time, restrictions of using the available resources of the holding, restriction on obtaining a certain quantity of physical production. The objective function of the model usually is the profit maximization.

In the case of the studied agricultural holding, the possibility of conversion of the conventional crops system to a sustainable one means to use the alternative cultural methods (abandoning monoculture), the soil organization for crops rotation and their succeeding (maize, wheat, sunflower), fertilization with natural nutrients, increase of the amount of manual works etc. The main elements of the ecological technology practised by the holding are illustrated in table 2 . 
Table no. 2

Specific indicators of the crop sustainable technology

\begin{tabular}{|l|c|c|c|c|c|}
\hline Crop succession & $\begin{array}{c}\text { Cultivated } \\
\text { area } \\
\text { (\% of total) }\end{array}$ & $\begin{array}{c}\text { Labour force } \\
\text { consumption } \\
\text { (days-pers/ha) }\end{array}$ & $\begin{array}{c}\text { Average } \\
\text { production } \\
\text { (to/ha) }\end{array}$ & $\begin{array}{c}\text { Contracted } \\
\text { production } \\
\text { (to) }\end{array}$ & $\begin{array}{c}\text { Average } \\
\text { profit } \\
\text { (RON/to) }\end{array}$ \\
\hline Maize & 60 & 14 & 4.5 & 600 & 140 \\
\hline Wheat & 55 & 4 & 3.0 & 160 & 250 \\
\hline Sunflower & 4 & 4 & 1.5 & 30 & 800 \\
\hline
\end{tabular}

The total labour force time is 6500 days-persons whose utilization cannot be lower than $10 \%$ without affecting the crops works.

The economic, technical and technological conditions are converted into mathematical relations within the linear programming model. We denote by $x_{1}, x_{2}, x_{3}$ the area cultivated with maize, wheat and sunflower.

- crop rotation restrictions:

$$
\begin{aligned}
& x_{1} \leq 480 \\
& x_{2} \leq 440 \\
& x_{3} \leq 32
\end{aligned}
$$

(7)

- the complete use of the soil within the crop rotation land:

$x_{1}+x_{2}+x_{3}=800$

(8)

- the rational utilization of the labour force:

$$
\begin{aligned}
& 14 x_{1}+4 x_{2}+4 x_{3} \leq 6500 \\
& 14 x_{1}+4 x_{2}+4 x_{3} \geq 5850
\end{aligned}
$$

(9)

- realize the commodity production established by contract:

$$
\begin{aligned}
& 4,5 x_{1} \geq 1400 \\
& 3 x_{2} \geq 1300 \\
& 1,5 x_{3} \geq 45
\end{aligned}
$$

- $\quad$ non negativity of the cultivated area:

$$
\begin{aligned}
& x_{1} \geq 0 \\
& x_{2} \geq 0 \\
& x_{3} \geq 0
\end{aligned}
$$

- the objective function of the model - the profit maximization: 
$\max f(x)=4,5 \cdot 1400 x_{1}+3,0 \cdot 250 x_{2}+1,5 \cdot 800 x_{3}$

The linear programming model can be resolved with Simplex algorithm and it will produce an optimum structure of the plant crops within the crop rotation land (table 3 ).

Table no. 3

Economic effects of crop rotation

\begin{tabular}{|l|c|c|c|c|}
\hline $\begin{array}{c}\text { Crop } \\
\text { succession }\end{array}$ & $\begin{array}{c}\text { Cultivated area } \\
\text { (\% of total) }\end{array}$ & $\begin{array}{c}\text { Labour force } \\
\text { consumption } \\
\text { (days-pers/ha) }\end{array}$ & $\begin{array}{c}\text { Total } \\
\text { production } \\
\text { (to/ha) }\end{array}$ & $\begin{array}{c}\text { Total profit } \\
\text { (RON/to) }\end{array}$ \\
\hline Maize & 330 & 4620 & 1485 & 207900 \\
\hline Wheat & 440 & 1760 & 1320 & 330000 \\
\hline Sunflower & 30 & 120 & 45 & 36000 \\
\hline Total & 800 & 6500 & 2850 & 573900 \\
\hline
\end{tabular}

Applying the crop rotation within the sustainable system has had favourable effects for all kind of compounds of the production systems that are specific elements of sustainable development.

In an economic view, there are maximum results for the holding taking into consideration the technical, technological, economic and ecological requirements. Therefore, the holding can observe all its beneficiaries' engagements, the physical crop obtained covers all production amounts established in contracts, and for every culture it registered a plus of harvest. Also, in a value expression, the earning is maximum, the total profit being of $573900 \mathrm{RON}$.

The social aspect of crops rotation practised can be seen at the human capital level. The labour force was valorised in an efficient way by introducing the rotation of cereals and sunflower, as the farming works has executed in accordance with the ecological technologies. The total employees time was fully used (6500 days-person); they will benefit of certain revenues resulted from the production and sale of the plant crops.

The favourable effects of the agricultural technique measure are also felt at the level of natural capital elements. The allocation of the arable land on the successive crops is at an optimum level and it is due to the rotation constrains and crops shares recommended by the farming technologies. Therewith, the respect of these conditions ensures the preserving and enhancement of one important natural factor, namely the land. The optimum allocation of crops has produced total use of the disposable lands, increase of the soil fertility because of the recurring succession of the cultures in time and space, so that, usually in these conditions the soil nutrients are preserved or maybe even increased [Brock, 2008].

The other elements for environment protection achieved with the help of crop rotation concern the decrease of water pollution, enhancing of the biological value of plants through combating weeds, pest or diseases, increasing the biodiversity of the agro ecological systems [Rădulescu, 2003].

\section{Conclusions}

Putting into practice of the conventional holdings of some agro technique measures which are selected based on the economic and ecological criteria, represents a way to turn the traditional productive systems into environmental-oriented ones. In this way, the characteristics of the European model for sustainable development are stressed at the microeconomic level of the agriculture sector.

The eco-efficiency actions are grounded on the introduction and extension of some measures which at the same time can ensure economic, ecological and social effects. They are part of the 
farming technologies that are very important conditions of initiating the culture cycles (soil melioration works) or can be applied in the productive process (fertilization systems, practising the crop rotation, technological works).

In order to attain the objective of improving the economic efficiency and social environmental performance of the holdings, it is necessary that the strategic decisions of the making-factors are well substantiated and to point aspects like resources saving, increasing of the performance of the productive factors, a lowest negative impact on the environment, use of the agricultural activities to sustain the preservation and enhancing of natural capital or for resolving some social aspects of the rural space.

The final results of the correlated actions for eco- efficiency are meeting the sustainable development requirements at the agricultural holdings level and they can ensure the functioning of some systems whose main features define them as economically efficient, socially acceptable and especially, not harmful for the environment.

\section{References}

1. Bijaya K.M.,Deepak K.D., Interactive Fuzzy Multi-objective Programming in Land Reorganisational Planning for Sustainable Rural Development, PWASET, vol.30, 2008

2. Brock, C., Leithold, G., The Impact of Site and Management Factors on Humus Dynamics in Long-term Field Experiments, Cultivating the future based on science, vol. 1, 2008

3. Gilcă F and collaborators, Memorator de planificare şi organizarea ştiințifică a producției în unitățile. agricole, CERES Publishing House, Bucharest, 1993

4. Nijkamp ap., Avindigni G., Food security and agricultural sustainability: an overview of critical success factors, Environmental Management and Health, nr.5/2002, http://emeraldinsight.com, (accessed in September 2008)

5. Rădulescu C.V., Dezvoltarea durabilă şi implicațiile economico-financiare ale organizării exploataţiilor agricole, ASE Publishing House, Bucharest, 2003

6. Voicu R., Dobre, I., Organizarea şi strategia dezvoltării unităţilor agricole, ASE Publishing House, 2003

7. Zahiu L. Management agricol, Economică Publishing House, Bucharest, 1999

*** The National Strategy for the Sustainable development of Romania, time horizons 2013- 2020-2030 http://strategia.ncsd.ro/docs/sndd, (accessed in October 2008) 